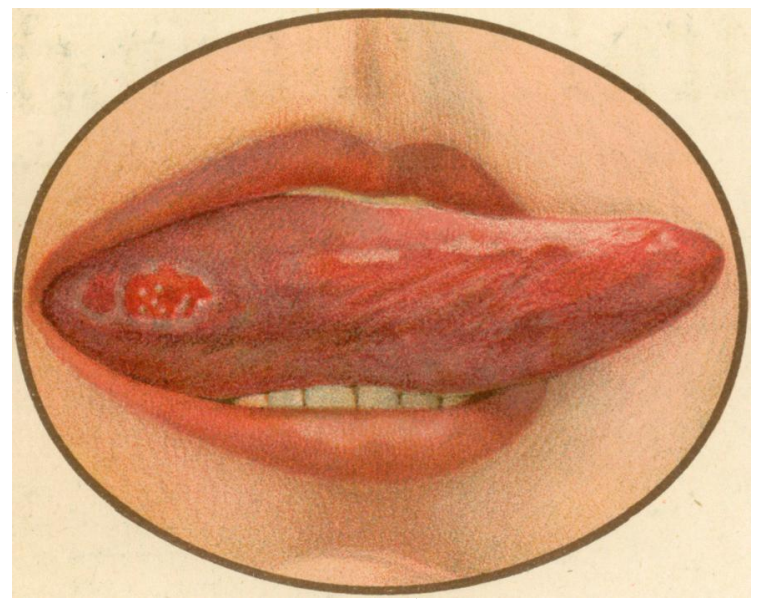

FIGI.

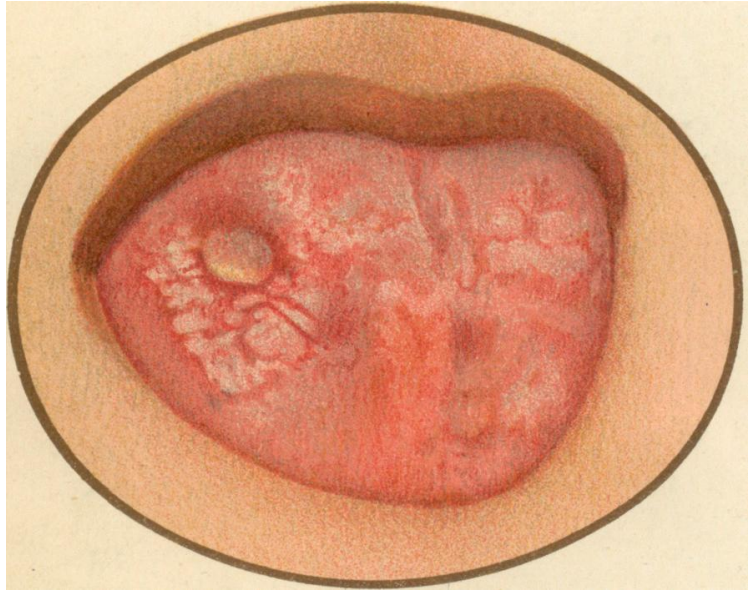

FIG II.

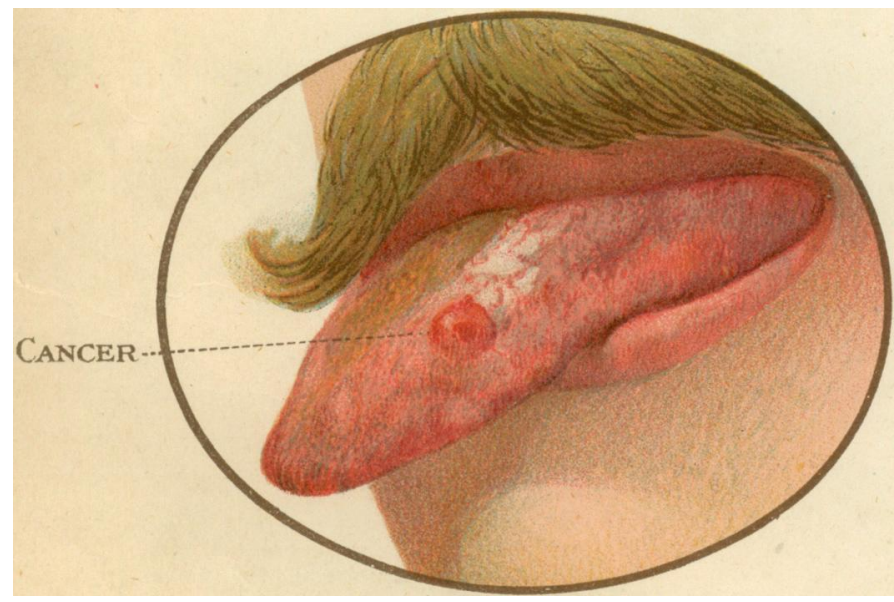

FIG III.

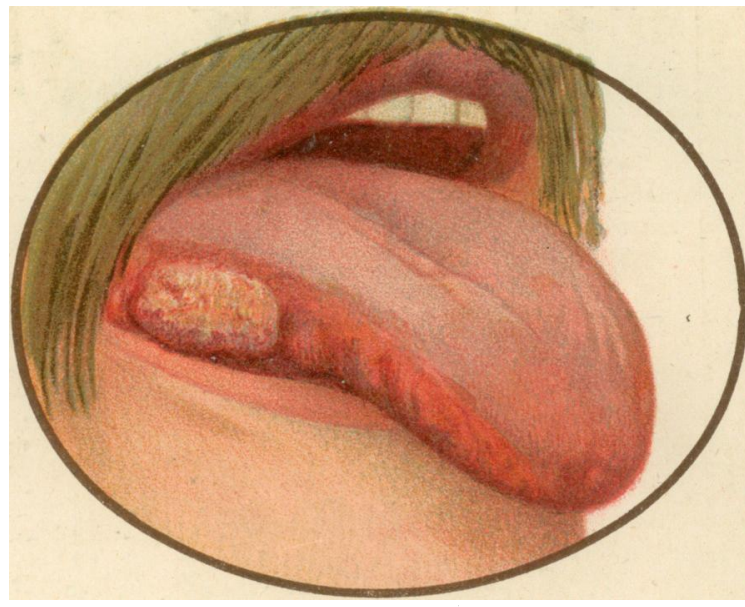

FIG IV.

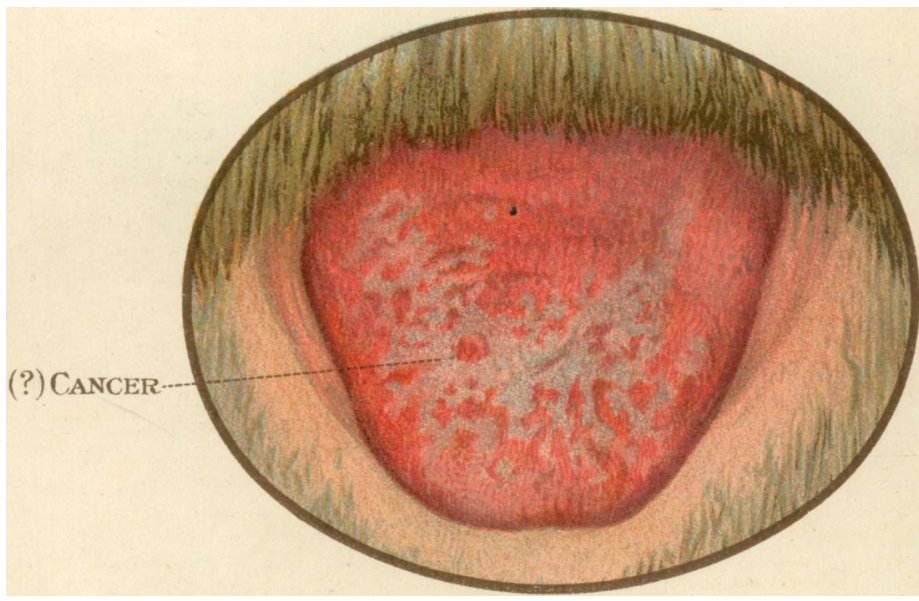

FIG V.

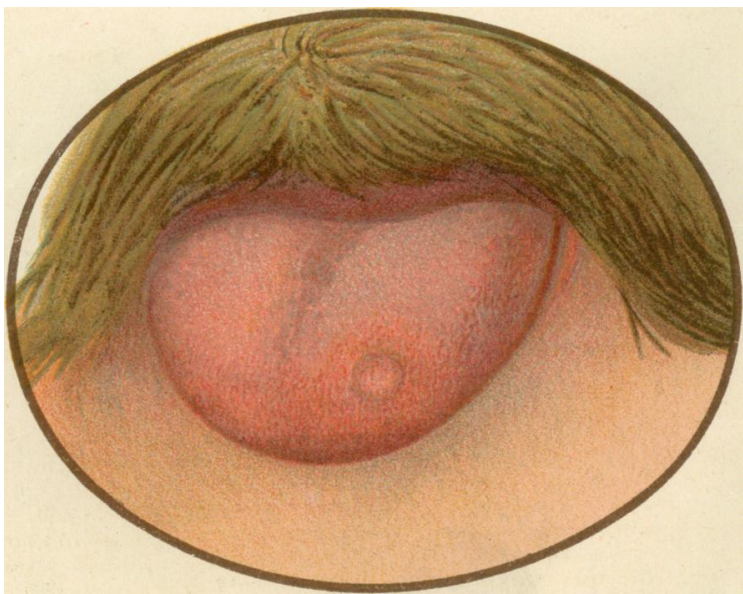

FIG VI. 
THE JOURNAL OF THE BRITISH MEDICAL ASSOCIATION.

LONDON: SATURDAY, JANUARY 2ND, 1909.

\section{An Andres:}

os

\section{THE RESULTS OF OPERATIONS FOR CARCINOMA OF THE TONGUE,}

\author{
WITH AN ANALYSIS OF 197 CASES.
}

Delivered before the International Surgical Society in Brussels, September, 1908.

By HENRY T. BUTLIN, F.R.C.S., D.C.L., CONSUL TING SURGEON TO ST. BARTHOLOMEW's HOSPITAL.

\section{[With Coloured Plate.]}

ORDER OF PAPERS.

I. Preliminary Remarks.

II. Total Results of 197 Cases.

III. Causes of Death from Operation.

IV. Successful Cases.

V. Comparison of Results of first 98 with second 99 Cases.

VI. Comparison of 70 Cases in which the Contents of the Anterior Triangle were Removed, with 44 Cases (during the same period of time) in which they were not Removed.

VII. Should the Operation on the Tongue and Glands be Performed at a Single Sitting?

VIII. Is there any Advantage in Postponing the Removal of the Glands until they are Enlarged ?

IX. Is the Removal of the Contents of the Anterior Triangle Sufficient as a Routine Procedure?

$X$. Is it Necessary to Remove the Glands on Both Sides of the Neck?

XI. Are there any Cases in which this is Necessary?

XII. Is it Necessary to Remove the Muscles to their Attachments on the Bones? (Cheatle's theory.)

XIII. Is it Necessary to Remove the Tissues between the Primary Disease and the Glands?

XIV. Is there any Part of the Tongue from which the Glands are less Liable to become Affected?

XV. Does Early Diagnosis render the Prognosis of Operation more Favourable?

XVI. Cancer of the Floor of the Mouth.

XVII. Operations for Recurrent Disease.
I.

I BELIEve that the following cases comprise all those in which I have operated for carcinoma of the tongue. The first operation was performed in 1881, and the last a few months ago (June, 1908).

In the year 1895 I first performed a planned operation for the removal of the contents of the anterior triangle of the neck, which was founded on the experience which I had gained from observation of the places in the neck in which the glands are most liable to be diseased. Since that time 70 patients have submitted to that operation. In 44 other patients it has not been performed for various reasons, chiefly on account of the difficulty of inducing the patients to submit to it.

The operations on the tongue have been performed almost entirely through the mouth, and the lower jaw has never been divided, although portions of it have been removed in a number of cases. The object of the operation has been to remove the disease together with, if possible, about three-quarters of an inch of surrounding healthy tissues.

At the commencement of the year 1900, I began to perform a preliminary laryngotomy before proceeding to the removal of the disease of the tongue. This operation has been performed in all cases since that time, amounting in number to between sixty and seventy. It is highlv to be recommended, for it has all the advantages of tracheotomy without the disadvantages. It can be performed in less than one minute. It enables the operator to deal much more deliberately and effectually with the disease of the tongue, however extensive this may be, and it enables the anaesthetist to pursue his duties without interruption.

The patients have been traced with great care, but the information which has been obtained respecting the further history of some of them is naturally defective. Thus, it has not always been possible to determine whether recurrence took place in the tongue or in the glands, or the exact relation which the recurrence bore to the disease which was removed. Even with these defects the results are very interesting, and I have tried to answer a number of questions by a careful analysis of them. The answers to some of the questions must not be regarded as final. Further experience may prove that they require

\section{DESCRIPTION OF COLOURED PLATE.}

Fig. 1.-From a doctor, aged 30 (Dr. H. D.). Old areas of leuccplakia on the fore-part of the border of the tongue. Excoriated, very slightly raised area further back, red and glossy, looking just as if it had been rubbed sore by a rough tooth. Has had ulceration here for some time, but the place only became a little harder a fortnight before I saw it. Examined by the. Imperial Cancer Research. (March, 1906.)

Fig. 2.-From a man, 70 years of age. Old leucoplakia, with a slightly raised, glazed, and granular epithelioma of short duration. Examined by the Imperial Cancer Research. Mr. F. (July, 1907.)

Fig. 3.-From a man, 60 years of age. Leucoplakia, with a red, smooth, circumscribed plaque, with a slight depression in the centre. It felt quite thin, like a little piece of parchment in the mucous membrane. It had only been noticed four or five weeks. On removal it was found to be almost $\frac{1}{4}$ in. thick, much more than On removal it was found to be almost $\frac{1}{4}$ in. thick, much more than
had been suspected. And, on microscopical examination, it had had been suspected. And, on microscopical examination, it had
infiltrated the muscles far below its apparent limit. Examined by the Imperial Cancer Research. Mr. A. (December, 1906.)
Fig. 4.-From a man, 60 years of age (Colonel $L$.). A white granular area of leucoplakia of many years' duration, which has recently become malignant. There is no ulceration or excoriation, but the plaque is harder than usual. Examined by the Imperial Cancer Research. The cancer cells were already beginning to pass
down between the muscular fibres. (June, 1908.)

Fig. 5.-From a man, aged 49 (Mr. C.). Old thin leucoplakia and chronic superficial glossitis, with one slightly raised spot, red like a pimple. This was suspected to be epithelioma, and was exbe sure whether it was or was not an epithelioma. (February, 1907.)

Fig. 6.-From a man, aged 40 (Mr. F.). Small raised, very firm tumour, very fixed in the surface of the tongue. The surface of the tongue was otherwise perfectly natural everywhere. Of about three
months' duration. Not red, glazed, excoriated or uloerated. Very
slightly rounded on the surface, otherwise like the top of an almost slightly rounded on the surface, otherwiselike the top of an almost flat button. Not granular or warty. About the same colour as the surface of the tongue, so that I did not at first notice it. On section, dense white, cutting like gristle, not looking like epithelioma, but more like fibrous tissue. Very circumscribed against the muscle Goldmann of Freiburg. (February, 1908.) 
modification. But, for the present, they may be taken as representing very truthfully my own views of the surgery of carcinoma of the tongue.

With regard to the cases themselves, it must be under stood that there has been no selection. Operation has been performed during the entire period of twenty-seven years on every patient who was deemed likely to be relieved by it, whether in hospital or private practice. Thus, while it has been my good fortune to operate on some very favourable cases, it has also been my misfortune to be called on to operate on a number of eases which proved to be quite hopeiess. On the whole my cases were probably no better and no worse than those which fall to the lot of every surgeon who is engaged pretty largely in this kind of practice. Although, naturally, most of the very bad cases have been failures, a sufficient number of them have been successes to encourage operators not to decline to operate on them. I have been astonished at the success which has attended resolute surgery in some of those in which the result seemed to be hopeless.

But the future of the operative surgery of carcinoma of the tongue undoubtedly lies in early diagnosis of the disease and in the routine removal of the glands before they are obviously enlarged.

\section{II.}

Results of 197 Cases of Cancer of the Tongue operated on by Mr. Butlin in Private and Hospital Practice between the Year 1881 and the present Year (June, 1908).

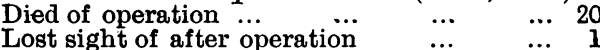

$$
\begin{aligned}
& \begin{array}{llll}
\text { Lost sight of after operation } & \ldots & \ldots & \mathbf{1} \\
\text { Died of recurrence in the mouth } & \ldots & \ldots & 26
\end{array} \\
& \text { Died of affection of glands without re- } \\
& \text { currence in the mouth ... } \quad \ldots \quad \text {... } 29 \\
& \text { Died of recurrence in the glands without } \\
& \text { recurrence in the mouth } \ldots \text { and glands } \ldots 10 \\
& \text { Died of recurrence, uncertain whether in } \\
& \text { mouth or neck or both ... ... } \quad \ldots \quad 10 \\
& \text { Died of affection of the glands, ancertain } \\
& \text { whether recurrence in the mouth } \\
& \text { Died of recurrence in the glands, uncertain } \\
& \text { whether recurrence in the moth } \ldots \\
& \text { Died of affection of glands on other side of } \\
& \text { neck } \\
& \text { of lungs } \quad \cdots \quad 2 \\
& \begin{array}{lllll}
\text { Total } & \ldots & \ldots & \ldots & \ldots \\
197
\end{array} \\
& \text { III. }
\end{aligned}
$$

Died suddenly during the operation $\quad \ldots \quad 1$

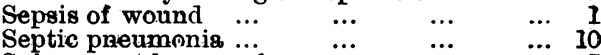
$\begin{array}{llllr}\text { Septic pneumnnia } \ldots . . & \ldots & \ldots & \ldots & 10 \\ \text { Subsequent haemorrhage } & \ldots & \ldots & \ldots & 3\end{array}$ $\begin{array}{lllll}\text { Subsequent haemorrhage } \ldots & \ldots & \ldots & \ldots & 3 \\ \text { Shock } & \ldots & \ldots & \ldots & \ldots\end{array}$ Suffocation (sudden, a week after operation) Heart-failure (some days after light operation

in feeble patient, aged 77 years) $\ldots . \quad \ldots$

Acute mania (wound doing well) $\ldots . \quad \ldots . \quad$ I

$$
\text { Total } \quad \ldots \quad \ldots \quad \ldots \quad \ldots \overline{20}
$$

One of the patients who died of haemorrhage was "a bleeder," and was acquainted with the fact, but concealed it as he wished to have the operation performed.

$$
\text { IV. }
$$

Successful Cases: Fifty-five Persons, whose Cases were traced for more than Three Years after the last Operation on Tongue or Glands.

$$
\text { Dead. }
$$

Caúse.

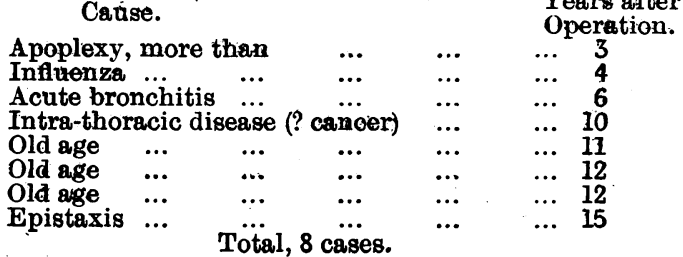

Traced for the following Periods after Operation.

No. of Patients.

$\begin{array}{cc}2 & \cdots \\ 2 & \cdots \\ 2 & \cdots \\ 2 & \cdots\end{array}$

Years aiter

Operation.

8 cases.

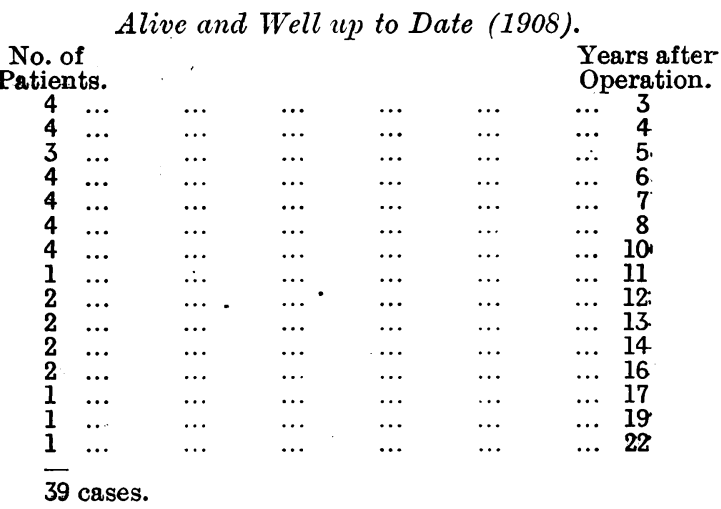

In addition to the above cases, 4 persons died of other disease than cancer of the tongue and glands between one and three years after the last operation, and 6 patients are still alive and well between one and three years after the last operation.

$\mathrm{V}$.

Comparison of Results between the first Ninety-eight Cases and the second Ninety-nine Cases.

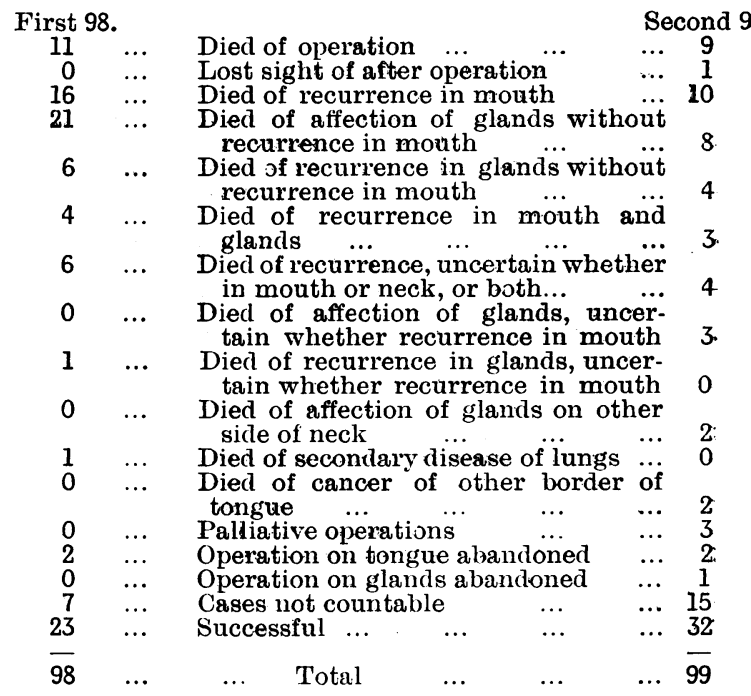

VI.

In the year 1895 I began the routine removal of the contents of the anterior triangle. Out of 114 cases since that time, I removed the contents of the anterior triangle in 70, and did not remove them in 44 cases.

\section{Analysis of the Forty-four Cases in which the Contents of} the Anterior Triangle were not removed.

(To these should be added 8 cases in which the patients returned at a later period for removal of enlarged glands, which were not intended to be removed when the tongue was treated, making a total of 52 cases.)

Died of operation $\ldots$ in the mouth (in 3 of $^{\circ}$ these the operation was abandoned)

Died of affection of glands (in:5 of these the glands were enlarged at theltime of operation on the tongue, but were not removed for various reasons)

Died of cancer of opposite border of tongue 15

$\begin{array}{llllll}\text { Cases not countable } & \ldots & \ldots & \ldots & 3 \\ \text { Successful cases } & \ldots & \ldots & \ldots & \ldots & 12\end{array}$

Total $\quad \ldots \quad \ldots \quad \ldots \quad \ldots \overline{44}$ 
Eight Cases in which the Glands were Removed at a Later Period because they became Enlarged.

(These cases are also included in the 70 cases of removal of the anterior triangle.)

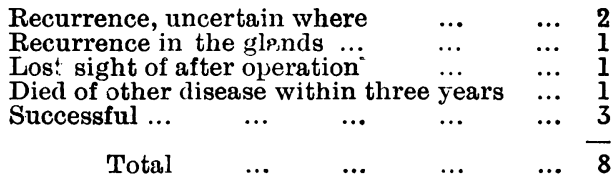

Six patients who died of the operation must be deducted from the total of 52 patients, leaving 46 patients. The glands are known to have become enlarged at a later period in $10+8=18$. In addition, they were enlarged at the time of operation on the tongue in 5 other cases, but were not removed. And there are 3 cases (not countable) in which they may still become enlarged.

The: percentage of successful cases out of the 44 patients for whom the glands were not removed is as 12 to 41 (for the three not-countable cases must be deducted from the total of 44$)=29.26$ per cent.

The causes of death from the operation were:

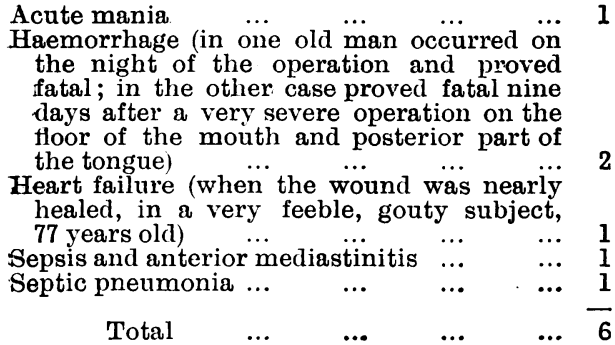

Analysis of the Seventy Cases in which the Contents of the Anterior Triangle were Removed.

Died of the operation

Lost sight of after operation $\quad \ldots \quad \ldots$

Died of recurrence in the mouth $\ldots . \quad \ldots .6$

Died of recurrence, uncertain where (in one of these the glands could not be entirely removed; operation abandoned) ...

Died of recurrence in the glands (in one of

these the submaxillary salivary gland was left and the disease recurred beneath it; in the other 7 cases the glands were enlarged at the time of their removal, and in 5 of these they were demonstrably

cancerous)
Died of cancer on the opposite side of the

tongue $\ldots \ldots$ affection of glands on opposite side of neck $\ldots \quad \ldots \quad \ldots \quad \ldots \quad \ldots$

Died of other disease within three years $\quad \ldots \quad$ l

Cases not countable $\quad \ldots \quad \ldots \quad \ldots .11$

$\begin{array}{llllll}\text { Successful cases } & \ldots & \ldots & \ldots & \ldots & 11 \\ & & \ldots & \ldots & & \end{array}$

$$
\text { Total } \quad \ldots \quad \ldots \quad \ldots \quad \ldots \overline{70}
$$

The successful cases are calculated on the 70 cases, after deducting cases not countable (11), the patient who died within three years of another disease (1), and the patient who was not traced after the operation (1), leaving 57 cases, with 24 successful cases $=42.01$ per cent.

The age of the patients operated on showed that 10 of them were over 65 years of age, and 1 over 70 years (77).

The causes of death from the operation were :

Haemorrhage, etc. (both from mouth and neck in a badly alcoholic patient)

Suffocation (from the sudden falling back of the root of the tongue some days after

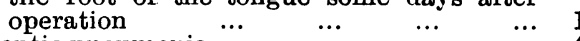

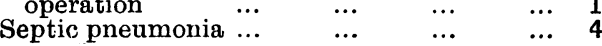

$$
\begin{array}{llllll}
\text { Total } & \ldots & \ldots & \ldots & & \\
& & &
\end{array}
$$

VII.

Should the Operation on the Tongue and the Removal of the Glands be Performed at a Single Sitting?

The 70 cases in which the contents of the anterior triangle removed may be tabulated as follows:

Sinole dting :

Glands enlarged $\ldots \quad \ldots \quad \ldots \quad \ldots \quad \ldots 12$

Gilands not enlarged $\quad \ldots . \quad \ldots . \quad \ldots \quad 10$

$\begin{array}{llllll}\text { Total } & \ldots & \ldots & \ldots & \ldots & \overline{22}\end{array}$

with 4 deaths due to the operation
Separate sitting (shortly before or after operation on the tongue):

Glands enlarged ...

$\cdots \quad \ldots \quad \ldots 16$

At a later period:

Glands enlarged

Glands not enlarged

...

Total

... 8

with 2 deaths due to the operation.

Total of the last two groups 48, with 2 deaths due to the operation. In one of these cases the operation on the glands was undertaken twelve days after the operation on the tongue, and a further portion of the tongue was cut out because I feared I had not removed sufficient at the first operation. This further portion was in the floor of the mouth, and the entire wound in the neck became septic.

It will be noticed that the glands were already enlarged in 12 of the 22 cases in which the two operations were performed at a single sitting, and this was one of the reasons why the operation on the glands was not deferred.

It will also be noticed that in 8 of the 10 cases in which the glands were removed at a later period they were enlarged. Indeed, the patients would not have submitted to the operation had the glands not been enlarged. In spite of this, all these 8 patients recovered from the operation, and in 3 out of the 8 the operation was followed by complete success. The following paper, however, shows that such success must be regarded as exceptional.

Is there any Advantage in Postponing the Operation on the Ghinds until they are Enlarged? *

For the consideration of this question, 56 cases, in which the results are known, may be used.

Glands enlarged at the time of operation, 34 :

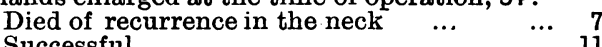

Glands not eniarged at the time of operation, ${ }_{22}{ }^{11}$ Died of recurrence in the neck $\ldots . . .$. $\begin{array}{cccccc}\text { Died of recurrence in the neck } & \ldots & \ldots & 1 \\ \text { Succ sssful ... } & \ldots & \ldots & \ldots & \ldots & 13\end{array}$

It will be seen that the evidence is largely in favour of not deferring the operation until the glands are enlarged.

In the single case of recurrence in the neck in the second series, the submaxillary salivary gland was not removed, but was raised up for the removal of the glands beneath it. Recurrence took place in the lower part of the salivary gland, presumably due to affection of a lymphatic gland which had been overlooked.

In the first series of 34 cases the glands were not obviously cancerous in the large majority of the cases, but they were so in some of the cases. Nevertheless, some of these patients were cured by removal of the cancerous glands, and remained well after many years. One case is especially worth recording in this respect. On June 8th, 1903, the right half of the tongue was removed from a gentleman, aged 56. At the same time the contents of the anterior triangle were dissected out. But a mass of glands beneath the great vessels was so fixed and the patient was so exhausted by the operation, that it was deemed inexpedient to persist in the attempt to remove them. On June 18th I summoned up my courage and again attacked the fixed glands, which were removed with considerable difficulty. The family doctor wrote me in April of this year (1908) to say that his patient is in perfect health, and has not had recurrence either in the tongue or in the glands.

If the operation were restricted, as it used to be, to the removal of glands which are obviously enlarged, the suggestion to defer the operation until the glands are enlarged would have some weight. But as the methodical removal of the contents of the anterior triangle is not restricted to the removal of the glands, but is extended to the removal of the tissues in which the glands are known to lie, the suggestion should not be accepted.

* This suggestion is made in a well-known English work on Surgica 
IX.

Is the Removal of the Contents of the Anterior Triangle sufficient as a Routine Procedure? Or, ought the Contents of the Posterior Triangle on the Same Side also to be Removed?

In my 70 cases there were very few in which the dissection was carried to the extent of removing the contents of the posterior triangle or of dividing the sternocleido-mastoideus. Yet there were only 8 cases in which the disease was noted to have recurred only in the neck.

In one of these the resurrence took place owing to the omission to remove the submaxillary salivary gland. And in the other 7 cases the glands were enlarged at the time of the operation; in 5 of the 7 they were macroscopically and microscopically cancerous.

I would recommend that the dissection should be carried into the posterior triangle in those cases in which the primary disease is seated far back on the border of the tongue; and in those cases in which the glands are badly affected in the parotid (upper carotid) region.

I would further advise that the dissection should always be carried well up to remove the glands in the parotid region. For this purpose it is necessary to remove the lower part of the parotid salivary gland. In one of my early cases of removal of the anterior triangle the patient died of the operation. At the autopsy an enlarged gland was found in this situation, which had not been removed at the operation.

\section{$\mathrm{X}$}

\section{Is it Necessary to Remove the Glands on Both Sides} of the Neck?

The cases of which $\mathcal{I}$ have notes are not sufficient in number for the decision of this question. There may have been other cases, among those of which the further history is imperfect, in which the glands were affected on both sides of the neck. So far as the records go, they do not favour the view of the necessity of subjecting every patient to the removal of the glands on both sides of the neck. They are as follows :

Cases in which the glands were affected on both sides of the neck $\quad . . \quad \ldots \quad$... 9

In 6 of these 9 cases both sides of the tongue were affected by the primary disease.

In the other 3 cases the primary disease was of one border of the tongue, and, in 1 of the 3, was some distance from the tip.

Cases in which the glands were affected only on the side opposite to the disease

In 1 of the 3 the primary disease was near the tip, and in another of the 3 it was about 1 in. from the tip. In both those cases the glands were removed from the opposite side of the neck only, and those 2 patients are alive and well many years after the operation.

$$
\begin{aligned}
& \text { Cases in which the glands on the opposite } \\
& \text { side of the neck became diseased after } \\
& \text { successful removal of the primary disease } \\
& \text { and the glands on the same side... }
\end{aligned}
$$

In both these cases the primary disease was situated on the border of the tongue, and was of rather small extent. It was some distance back on the border in both cases. It showed microscopic signs of excessive malignancy in one of the cases.

\section{XI.}

If it is not Necessary to Remove the Glands on Both Sides of the Neck in every.Instance, are there Cases in which this Procedure is Desirable?

The following conditions appear to me to call for wider removal of glands :

(i) Those cases in which the glands on both sides of the neck are enlarged.

(ii) Those cases in which the glands are affected only on the side of the neck opposite to the disease.

(iii) Those cases in which the disease is seated on both sides of the tongue, or in which it reaches to the middle line of the tongue.

(iv) Probably it ought to be done in those cases in which microscopical examination gives reason to believe that, although the primary disease is apparently only of small extent and depth, it is much more malignant than usual ; when, for instance, columns of cancer cells are found running deeply down between the muscular fibres.

\section{XII.}

Is it Necessary in all Cases to Remove the Muscles to their Attachments?

(During the last two or three years researches on the spread of cancer of the tongue have been made by $\mathbf{M r}$. Lenthal Cheatle, C.B. He has found, in microscopic sections of the muscles at a considerable distance from the primary disease, columns of cancer cells lying between. the fibres of muscles, which look quite healthy to the naked eye. He therefore recommends that, according to the seat of the primary disease, the genio-hyoglossus and inferior lingualis or the hyoglossus or the stylo-glossus muscle should be removed back to its attachment to the bone. In cases of cancer of the anterior part of the tongue and the tip, the genio-hyoid muscle and the fascia. covering it should be removed. If the primary disease is so situated as to extend into both halves of the tongue, some or all of these muscles should be removed on both sides. As the result of his researches Mr. Cheatle is of opinion that the hyoglossus and genio-hyoglossus and inferior lingualis muscles should be removed in every case of cancer of one half of the tongue, even if the primary disease is quite small and in an early stage of its existence.)

Out of the 197 cases there were 99 in which there was no recurrence in the tongue. They are classified as follows :

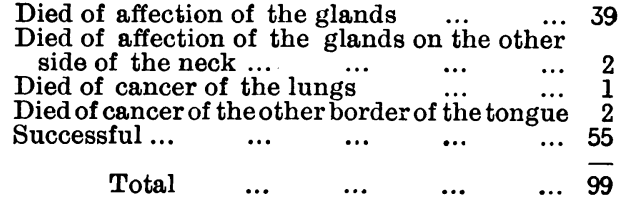

In addition to these 99 cases there are a number of other cases which cannot be counted because less than three years have elapsed since the operation. But as from two to three years have elapsed in many of them there is now no reason to apprehend recurrence in situ.

On the other hand there were 33 cases in which the disease is known to have recurred in the mouth. Most of them are noted as bad or extensive cases; in seven of them the floor of the mouth was affected to a greater or less extent ; and in only three of them was the disease of such small extent that I felt afterwards that it would not have recurred in the mouth if it had been more widely removed.

Although these figures do not support Mr. Cheatle's suggestion, I think it will be desirable to carry it into effect in the more advanced cases, especially in those in which the disease lies beneath the border of the tongue and passes into the floor of the mouth.

The objections to it in addition to the larger operation which it involves, are that the mobility of the tongue has been, in those few cases in which I have practised it, seriously impaired, and in consequence speech and mastication have not been nearly so good as in those cases in which the disease has been merely cut out without reference to the complete removal of individual muscles.

\section{XIII.}

Is it Necessary to Remove the Tissues between the Primary Disease and the Glands?

Although I cannot answer this question decidedly in the negative, the evidence in favour of this course is not, in my opinion, strong enough to justify the extra risk involved. For, in order to carry it out methodically and completely, it would be necessary to remove the primary disease and the glands in one continuous mass. In all but a few cases, the large wound in the neck, in which the great vessels and nerves are exposed, would suppurate, in most cases badly. The risk to life would therefore be very largely increased, and should not be incurred unless a very decided advantage can be claimed for the procedure.

Out of 70 cases in which the anterior triangle was completely cleared out, and a number of other cases in which glands were simply dissected out because they 
were enlarged, I have very rarely removed the primary disease and the glands in one continuous mass. Yet 29 of these cases proved to be successful. And out of a large number of the unsuccessful cases, in which recurrence took place either in the mouth alone or in the mouth and neck, and in which the seat of the recurrence was noted, there are only two in which it could reasonably have been attributed to affection of the tissues which were left behind between the primary disease and the glands.

Is there any Part of the Tongue from which the Glands are less liable to become Affected?

In 23 cases out of the entire series of 197 only the primary disease was removed, but the patients remained free from recurrence in situ and from affection of the glands (successful cases)

The seat of the disease, roughly noted, was as follows:

$\begin{array}{cccccc}\text { Dorsum : } & & & & & \\ \text { Anterior } & \ldots & \ldots & \ldots & \ldots & 8 \\ \begin{array}{c}\text { Further back } \\ \ldots\end{array} & \ldots & \ldots & \ldots & 2 \\ \text { Border: } & & \ldots & \ldots & \ldots & 1 \\ \text { Near the tip } & \ldots & \ldots & \ldots & \ldots & 4 \\ \text { At various points } & \ldots & \ldots & \ldots & 7 \\ \text { Beneath the border } & \ldots & \ldots & \\ \text { Tip : } & \ldots & \ldots & \ldots & 1 \\ \text { Under surface } \ldots & \ldots & \ldots & \\ \text { Total } & \ldots & \ldots & \ldots & \ldots & 23\end{array}$

For comparison with these cases, I have taken 23 cases (between the 87th and the 197th) in which the glands were not removed, but became affected at a later period:

$\begin{array}{llllll}\begin{array}{l}\text { Dorsum : } \\ \text { Anterior }\end{array} \quad \ldots & \ldots & \ldots & \ldots & 4 \\ \text { Border: } & & \ldots & \ldots & \ldots & 5 \\ \text { Near the tip } \ldots & \ldots & \ldots & \ldots & 9 \\ \text { At various points } & \ldots & \ldots & \ldots & 2 \\ \text { Beneath the border } & \ldots & \ldots & \ldots & 2 \\ \begin{array}{c}\text { Fraenum } \\ \text { Extensive disease }\end{array} \ldots & \ldots & \ldots & \ldots & \ldots & 1 \\ \text { Total } & \ldots & \ldots & \ldots & \ldots & 23\end{array}$

In addition to the case which is classed as extensive, because its point of origin was not ascertained, there were several cases in both series in which the disease of the tongue was extensive, but it was possible to determine the point at which it had first appeared.

Perhaps the anterior part of the dorsum is the least dangerous seat of cancer, qua affection of glands. But the results of the second series of cases show that it would not be safe to rely on a special immunity of that part in practice. In one of the cases the primary disease was of quite small size, and had only been noticed a short time.

\section{$\mathrm{XV}$.}

Does Early Diagnosis render the Prognosis of Operation more Favourable?

Very small and, presumably, recent cancers were removed in 18 of my cases. They were seated in different parts of the tongue, so that no conclusion can be drawn with reference to the seat of the disease. The results were as follows:

$$
\begin{aligned}
& \text { Recurrence in situ ... } \ldots \text {. } \ldots \quad \ldots \quad 2 \\
& \text { Died some years later of cancer of the } \\
& \begin{array}{c}
\text { opposite border of the tongue } \ldots \\
\text { Died of affection of glands without recui- }
\end{array} \\
& \text { Died of affection of glands without recui- }
\end{aligned}
$$

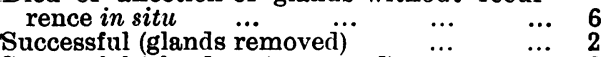

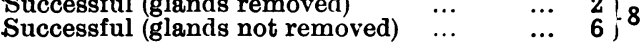

$$
\begin{aligned}
& \begin{array}{llllll}
\text { Total } \ldots & \ldots & \ldots & \ldots & \ldots & 18
\end{array}
\end{aligned}
$$

It will be seen that the percentage of successes, 8 in 18, was 43.33. And, in 6 of these cases, the operation was restricted to removal of the primary disease.

On the other hand, no fewer than 6 of the patients died at a later period of affection of the glands without recurrence in the tongue. This furnishes very strong evidence of the necessity of removing the glands even in cases of quite small and recent cancer of the tongue.

With regard to the 2 cases of recurrence in situ, 1 of them occurred many years ago, and the operation was not as wide as $I$ have been in the habit of practising since that time (largely on account of the failure which followed this particular operation). In the other case there is reason to believe the cancer was much more virulent than usual, for the operation which was practised would have sufficed for any but a virulent case.

XVI.

Cancer of the Floor of the Mouth.

An impression generally prevails among surgeons that cancer which originates in the floor of the mouth is peculiarly dangerous to life.

The following facts may serve to correct this impression, which I formerly held in common with my surgical colleagues :

$$
\begin{aligned}
& \text { No. of cases occurring in my practice, } 9 \text { : } \\
& \text { Died of recurrence in the mouth ... . . } \\
& \text { Died of affection of the glands without }
\end{aligned}
$$

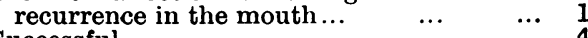

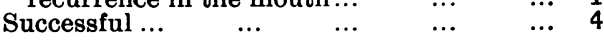

$$
\begin{aligned}
& \begin{array}{llllll}
\text { Total } & \ldots & \ldots & \ldots & \ldots & 9
\end{array}
\end{aligned}
$$

In all the 5 unsuccessful cases the disease was seated at or close to the fraenum linguae, and in 3 of them had invaded the bone, so that a portion of the jaw had to be removed. These cases were, therefore, peculiarly unfavourable for operation.

In 3 of the 4 successful cases the disease was also situated at the fraenum, but it was not adherent to the bone. In 2 of these cases the glands were removed shortly after the operation on the floor of the mouth. These 2 patients are both well at the present time, three years after the operation. In the third case the glands were not removed, and the patient remains well ten years after the operation. In the fourth case the cancer was of very small size, seated beneath the front of the tongue, where it joins the floor of the mouth. It was freely removed, but the glands were not dissected out. That patient is still alive and well, at the age of 79 , twenty-two years after the operation.

From these facts it may fairly be assumed that cancer originating in the floor of the mouth can be removed with a good prospect of success, provided it is not very extensive and has not involved the bone. But the two cases in which the operation was successful, although it was limited to the removal of the disease in the mouth, must not be taken to encourage operators to refrain from removing the glands. In most of the cases they were either affected at the time of the operation or became affected with the recurrence of the disease in the mouth.

\section{XVII.}

Operations for Recurrent Disease.

Tongue.-Only in five instances has there been an operation for recurrence of the disease in the tongue, and in one of these the disease was not truly recurrent. In 1890 the right border of the tongue was removed for epithelioma. The patient was a very free liver, drank and smoked a great deal. In 1900 some white plaques were removed from the same border of the tongue, but no cancer was found in them. In 1905 (fifteen years after the first operation), he had an epithelioma of the same border, with enlargement of the glands. An attempt was made to remove the disease by one of my colleagues, but the operation was not successful and the patient died in June, 1906.

All these operations for recurrent disease in the tongue were performed in the first 70 cases, 4 of them in the first 30 cases. The disease was not as thoroughly removed as in the cases during the last fifteen or more years. Not one of these lives was saved by the second operation. Two of the 4 patients died of recurrence in the tongue; the other 2 died of affection of the glands, which had been imperfectly removed in both cases.

Glands.-Eight patients were operated on for recurrence in the glands. Again, it is noticeable that 7 of these cases occurred in the first 90 cases, and only 1 in the remaining 107; in that case the submaxillary salivary gland was left for cosmetic purposes, with disastrous result.

The lives of 2 of these 8 patients were saved. The first was an old man, from whom the anterior part of the tongue and some enlarged glands were removed in September, 1893. In May, 1894, two glands were enlarged at the angle of the jaw, and were removed. He came to see me 
in 1902-eight years after the second operation-very well, but very feeble from old age.

The second of these patients was a woman from whom one side of the tongue was removed in October, 1894. In December of the same year two or three enlarged glands were removed, and in the following February (1895) some more glands. She remains quite well up to the present time-a period of more than thirteen years.

The results of operations for the removal of recurrent disease, whether of the tongue or glands, have been so bad that operators are counselled to make the first operation as complete as possible, in the belief that the only hope of the patient lies in the thorough manner in which this operation is performed.

\section{THE OPERATIVE TREATMENT OF INTRAORAL CANCER :}

WITH SPECIAL REFERENCE TO THE CHOICE OF OPERATION, ORDER OF OPERATION, AND LIGATURE OF THE LINGUAL AND FACIAL ARTERIES.

FROM AN EXPERIENCE OF THIRTY-NINE CASES.

By CHARLES P. CHILDE, B.A., F.R.C.S.,

SENIOR SCRGEON, ROYAL PORTSMOCTH HOSPITAL; SENIOR SURGEON, MEDICAL AND SCRGICAL HOME FOR WOMEN, SOUTHSEA.

FEw surgical diseases offer a wider choice of operative procedure for their cure or relief than carcinoma within the oral cavity. There are those surgeons, for instance, who strongly advocate a preliminary laryngotomy or even tracheotomy, others who have never found any necessity for their performance; those who favour preliminary ligatare of the linguals, others who never practise it and speak disparagingly of it; those who recommend the operation on the tongue and neck at one sitting, others who usually do it in two; those who remove first the tongue and later the glands, others who remove first the glands and later the tongue; those who perform Kocher's operation, which entails a communication between a septic wound in the mouth and an extensive recent wound in the neck, others who see grave objections to it on these grounds; those who frequently divide the lower jaw, others who consider it seldom necessary; and so on. The purport of the present communication is to consider the modern surgical treatment of intraoral cancer, in conjunction and in comparison with my own experience in dealing with it, with the view, if possible, of indicating what appear to me to be the most rational and practical methods to adopt. I assume that the following general statements and principles will be subscribed to by all modern surgeons.

1. The Necessity of a Wide Local Removal.-This will usually mean the sacrifice of not less than half the tongue, frequently of the whole congue, sometimes of a considerable portion of the floor of the mouth, part of the lower jaw, even exceptionally of the upper jaw, side wall of the pharynx, etc., according to the position and extent of the growth. Wherever the disease is situated, to be considered at all hopefully operable, it must be capable of a wide tocal removal, and I mean by this an excision which ensures a wide margin of apparently healthy tissue attached all round the growth. This is an important point, because cancer, distressing enough in any situation, is so peculiarly distressing in the mouth that, even as a palliative measure, to secure a non-recurrence in situ must be a particular aim of the surgeon. In carrying out this principle weare hampered considerably by the limitation of the cavity of the mouth; there is not the same scope for cutting wide of the tumour as in the breast for instance. If the disease, therefore, is so advanced, or so situated, or so fixed as to be incapable of a wide local removal, then in my opinion it is inoperable, because though a patient, after the dangers have been explained to him, is quite justified in risking his life in an attempt to be rid of such a terrible disease as cancer in the mouth; and though the surgeon, who knows the full extent of the misery which is in store for him is quite justified in urging him to undergo this risk, yet if the disease is to return in situ within a few weeks or months and his misery is to begin all over again, it is better to let him die once than twice, and not subject him to the trial of a serious operation into the bargain. Of course, the surgeon cannot guarantee against local recurrence, for apparently healthy tissue may contain cancer cells, but he should have this prospect particularly in view in recommending or discountenancing operation, and in whatever operative procedures he adopts. If, on the other hand, recurrence takes place in the neck, even within a short time, the case is different. The disease here, distressing enough, is so much less so than in the mouth that the intraoral operation will have been worth the doing, though if it has taken place in an early stage the patient, who will be ignorant of the misery he has escaped, will not fully appreciate the surgeon's effort.

2. The necessity of a wide glandular dissection in all cases in accordance with the modern principle of treating cancer surgically. This entails the removal of the fascia, fat and lymphatics from the submaxillary triangle (including in all cases the submaxillary salivary gland), and from the anterior triangle, down to the sheath of the great vessels, as well as the deep chain of lymphatic glands beneath the sterno-mastoid, from the clavicle to the atlas. The necessity of performing this extensive operation on both sides in all cases has not been finally determined. If the disease crosses or even approaches the mid-line in the tongue or floor of the mouth it is demanded; it is also demanded if the disease, though unilateral, is situated towards the base of the tongue, because there is a free communication across the mid-line between the lymphatics of that part. If the disease is situated anteriorly and is strictly unilateral the general opinion is that a dissection of one side is enough. Sufficient evidence to settle this question is not at present forthcoming, and surgeons and pathologists should direct their attention to it. Da Costa has recently recorded a case in which, the primary disease being strictly unilateral, the glands on both sides of the neck were secondarily affected. The matter is an important one for decision, because a bilateral neck dissection adds considerably to the severity of the operation.

3. Consequent on (1) and (2), the operation is very severe and serious. But there are other well-recognized circumstances which make it especially dangerous Patients with cancer in the mouth are usually getting on in life; they are frequently quite old; they are often the subjects of past syphilis, over-indulgence in tobacco and alcohol, as well as of the bronchial troubles that attend advancing years. They are not, therefore, the best subjects for major operation. In addition, there are special dangers attending the operative procedare itself. There is during the operation the danger of haemorrhage and of asphyxia owing to the entry of blood into the air passages. Subsequently, there is the danger of shoek, of inhalation pneumonia, and of septic cellulitis owing to communication in some of the operations-Kocher's, for instance-of a septic wound in the mouth with a large recent wound in the neck. Lastly, excision of the tongue is an operation in which the psychic element is an unfavourable factor. The idea of losing his tongue, even in a successful operation, is depressing to the patient, and probably influences the result in some cases. The causes of a high primary mortality, therefore, are not far to seek, and the importance of avoiding those that are avoidable must be kept in view in determining the choice and scope of operation.

4. The desirability of performing this operation as of all operations at one sitting if possible. A patient will sometimes be able to screw his courage up to face a single operation who cannot be brought to face a second. This object nevertheless, however desirable, is frequently unattainable in cases of mouth cancer.

5. The desirability of avoiding a communication between a wound in the mouth which is necessarily septic and a large wound in the neck which otherwise there is no difficulty in keeping aseptic.

6. The desiravility of not introducing any unnecessary procedures into an operation which of itself is quite complicated enough. Assuming that these statements and principles are correct, the practical question is how best to conform to them in the operative treatment of intraoral cancer. 